\title{
Personal Innovativeness and Perceived System Quality for Information System Success: the Role of Diffusability of Innovation
}

\author{
Aygul DONMEZ-TURAN* ${ }^{*}$ Cemal ZEHIR
}

\begin{abstract}
In the present study, the researchers aim to explain diffusion of innovation on the basis of technology acceptance as well as adaptation to information technology innovation, and put forward the relationships with perceived system quality and personal innovativeness as its antecedents and system usage as its consequence for information system success. Following previous studies, electronic document management systems' diffusability and employing such systems are the subject of this research. Having gathered the data from 262 administrative personnel working at a state university, we first conducted explanatory and confirmatory factor analyses on each scale, then constructed the measurement model and structural model. Results indicated that diffusability of innovation partially mediated the relationship between personal innovativeness and information system success measured by system usage. In addition, diffusability of innovation fully mediated the relationship between perceived system quality and information system success. Present research has been designed to explain management information system success with individual and system related factors, personal innovativeness and system quality, respectively. In addition, as a reflective construct diffusability of innovation has been defined on the basis of formative construct of diffusion of innovation and all its dimensions have been examined as a single latent construct, unlike the previous researches.
\end{abstract}

Keywords: diffusability of innovation; diffusion of innovation; information system success; perceived system quality; personal innovativeness; system usage; technology acceptance model

\section{INTRODUCTION}

Organizations continuously invest in computer and information technology infrastructures in the pursuit of systems that outcompete their current ones. In the knowledge management literature, such ordinary conversion of systems has been analyzed either technically or behaviourally, with a focus on the system users. The attitudes and behaviours of users, particularly when facing a new system, have been frequently researched. There are many studies in the literature showing that users, accustomed to the current system, have difficulty in accepting [1] and even show resistance to using the new system and thus undergo adaptation difficulties [2].

The difficulties faced by the users in adapting to the new system are explained in the literature through the constructs of technology acceptance, adapting information system innovation and diffusion of innovation $[2,3]$. Following these formative constructs, present research evaluated diffusion of innovation in a reflective way and entitled it diffusability of innovation, and also examined all dimensions of the construct as single latent construct. All of the relevant constructs endeavoured to predict individuals' attitudes towards a new system, technology or innovation, whether to gain acceptance or to meet resistance. The concepts of management information system success or implementation system success have been crucial topic to investigate since 1970s [4], so a great deal of concepts such as individual differences, user involvement, and also system related variables have been taken into account to explain the success [5]. Subsequently, some of the researchers evaluated technology acceptance or system usage as indicators of success of the system [6, 7]. On that point, the researchers attempt to explain management information system success with individual and system related factors.

Employees' adaptation difficulties may be caused either by system-related problems or by the individuals' intrinsic proneness to innovation, innovation creativity capabilities, and other individual factors. In this study, therefore, diffusion of innovation has been explained by two components: system quality and personal innovativeness, which was originated from the differences in cognitive styles of individuals [8]. Furthermore, a new system or technology would be used to facilitate processes in the event that it is accepted. The use of a system proves its usage, so usage is seen as the consequence of innovation diffusion.

Some researchers explored the differences between employees working in public and private sectors in terms of their reward preferences, motivation [9], innovative attitudes and motivation to promote innovation [10] etc. On that perspective, Wise [11], evaluating adoption of individuals to innovative practices differentiated employees working in public sector from those in private sector. Considering public personnel's low and limited usage to information and communication technologies [12, 13], present study has examined the public personnel's style of work and adaptation of a new system or diffusability of innovation, electronic documentation management system.

After an electronic documentation management system was implemented by many government institutions, employees in those institutions had difficulty in accepting this technology. Following previous studies, electronic document management systems (which facilitate document sending, receipt, undersigning, and similar processes of the personnel employed in public companies) are assumed to be a form of innovation for public personnel, and their adaptation to such systems is the subject of this research. The scope of the study is the administrative personnel using an electronic document management system in a state university located in Istanbul. In this framework, the electronic document management system in the state university - along with the problems faced by the personnel in transitioning to that system, their perceptions related to the system and attitudes towards using the system and the critical components in the process of system adaptation as well as diffusability of innovation - are the issues that will be addressed. So, researcher has discussed the issue on theoretical framework first, and then analyzed the research model which was put forward on implications of previous researches and the gap of the literature grounds. 


\section{CONCEPTUAL FRAMEWORK AND HYPOTHESES DEVELOPMENT}

The personal approach to acceptance of technology has been termed differently by different writers and defined in various dimensions. This concept, known as the technology acceptance model, was later defined as adaptation to information technology innovation and diffusion of innovation. In the process of transition from the technology acceptance model to the innovation diffusion model, the definitions related to the attitude of the individual toward system employment have shown cumulative developments. Thanks to its contributions to the technology acceptance model, such developments will be referred to below.

\subsection{Evaluation of Diffusion of Innovation Theory and Diffusability of Innovation}

Employees use different systems to carry out their obligations within the organization. These systems are revised or even replaced periodically by new systems due to deficiencies of the current system and advantages offered by the new system. Thus, technology acceptance is an important issue with regard to employees' adaptation to a new technology and system. The technology acceptance model, first referred to in the literature by Davis [1], was tailored to the theme of studying users'/employees' attitudes towards any system or technology installed by organizations. In this model, Davis [1] used the dimensions of perceived usefulness and perceived ease of use to explain the attitudes and behavioural intention of the users towards employment of any technology or system. The perceived usefulness in this model referred to whether the system improves employee performance; on the other hand, the perceived ease of use referred to whether it facilitates the operations of the employees while performing their duties. In other words, an individual's belief that the system improves job performance is the perceived usefulness, while his or her belief that it does not take much effort to use the system is the perceived ease of use [1].

Interpretation with regard to technology acceptance could be made considering individuals' perceptions on systems. Later studies in the literature analyze the information system success of a system through the attitudes of individuals towards the system, their intentions to use the system [4] and their current as well as actual use of the system $[6,7,14]$. Present study has also evaluated current use as an indicator of the success of the system.

Diffusion of innovation theory, put forth by Rogers [3], related to innovation diffusion through the organization, business or business process. The aim of the theory is to describe the adaptation of the employees to the new system, as is the case in the technology acceptance model. Rogers [3] defined diffusion of innovation in five dimensions, namely relative advantage, complexity, compatibility, trialability and observability. Later, Moore and Benbasat [2] added the dimensions of image and result demonstrability. Here, relative advantage describes the contribution of the innovation to the job performance of the employees. In fact, this dimension corresponds to the concept of perceived usefulness stipulated in the technology acceptance model set forth by Davis [1]. The dimension of complexity can be linked to the perceived ease of use referred to by Davis [1], meaning that no extra effort is necessary with regard to learning and using the introduced system (innovation). Rogers [6, s. 195] defines the compatibility dimension as "the level of consistency of the innovation with the current values and requirements and their experiences". The dimension of image relates to users' perception with regard to employment of the relevant system as a status indicator. Result demonstrability refers to concrete outputs after employment of the system, while observability refers to the ability to observe innovation indicators in the process of adaptation. Finally, the dimension of trialability implies to the potential users' ability to try the system before adaptation of the innovation. Although many researchers define the technology acceptance or innovation adaptation process using these dimensions, in fact, volunteering is one of the most important subjects in the process of technology acceptance and innovation adaptation or diffusion [2].

Ma and Liu's [15] meta-analysis about technology acceptance literature showed the strong correlation between perceived usefulness (relative advantage) and ease of use (complexity) dimensions of technology acceptance model. Recent studies about technology acceptance as well as the follower theories of technology acceptance such as unified theory of acceptance and use of technology have evaluated the dimensions of technology acceptance as a latent construct, owing to the strong correlation among the dimensions. Following these results, Thakur and Srivastava [16] concluded that perceived usefulness, ease of use, facilitating conditions and social influence dimensions of unified theory of acceptance and use of technology could be evaluated as a single latent construct and entitled as adaptation readiness. They explained "the extant literature thus makes us deduce that these factors are not really independent constructs affecting one-another but they are actually dimensions of a single construct". Following the previous, especially, Thakur and Srivastava's research [16], we evaluated the dimensions of diffusion of innovation as one latent construct named as diffusability of innovation in present research. In addition to that, the concept of diffusability of innovation represents the ability or availability of diffusion of a new system, technology or innovation. In the literature, diffusion ability has been used as elements or compounds diffusability into some context in chemistry or biology [17]. Only the Le Roux's [18] research investigating the potential problems of nano-technological biochips diffusability across individuals has mentioned diffusability of an innovative product, so this study motivated present researchers to put forth diffusability of innovation concept and examined it reflectively.

\subsection{System Usage as an Indicator of Information System Success}

Management information success as a concept has been examined and evaluated for decades by a large number of researchers. Furthermore, DeLone and McLean appraised the concept on the technology acceptance framework and claimed system quality, information quality [6] and then service quality [7] determined the information system success. In addition, DeLone and McLean [6, 7] claim system usage is an appropriate measure of success. Hence, system usage continues to be used as dependent variable at subsequent empirical studies 
of information system success or system implementation success $[14,19]$.

Rogers [3] as well as Moore and Benbasat [2] alleged diffusion of innovation dimensions (relative advantage, ease of use, compatibility, image, result demonstrability, visibility and trialability) were important for individual use of a system theoretically; then Agarwal and Prasad [20] defined these dimensions as innovation characteristics and represented their influences on acceptance outcomes as current use and future use intention, empirically. Parallel with the Agarwal and Prasad's study [20], one of the study examining the diffusion of e-government services presented empirical evidence that relative advantage as well as compatibility of the system is crucial for citizen's intention to use [21]. The research explaining intention to use has confirmed the Agarwal and Prasad's [20] and Carter and Belanger's results of the researches [22]. Furthermore, Rana et al. [23] conducted meta-analysis to indicate theories explaining e-Government systems' adoption, such as technology acceptance model, diffusion of innovation, theory of reasoned action etc. They indicated that compatibility, relative advantage, complexity and image dimensions of diffusion of innovation had significant relationship with citizen's intention to use the system.

Diffusion of innovation theory is not only examined on adaptation of a new technology or system, but also investigated on infusion of an innovation other than technology, in the literature. For instance, Chang et al. [24] examined attitudes towards nano-foods as well as willingness to trial by customers on the basis of diffusion of innovation and social capital theory. Another one is bike share programs evaluated as an innovation and investigating its diffusion to Canadian residents by Therrien et al.'s [25], and they reached to three categories of participants as leaders, majority and resisters according to the usage of that program.

Evaluating information systems literature, Carter et al. [26] argued that individual adaptation causes individual use which triggers group adaptation, and group adaptation leads to group use which triggers organizational adaptation that results in organizational use. After that, numerous studies have been conducted to quest individual adaptation with the aim of group or organizational adaptation, so those represented the information system success [27]. Chang et al. [24] explained nano-foods attitudes of consumers and trial of them on the basis of three features as innovative, consumer and social features. In present study, management information system success has been explained on the basis of systematic (system quality), individual (personal innovativeness) and innovative (diffusability of innovations) features.

\subsection{Perceived System Quality}

System quality is an estimation of the technical and design qualities of a system [28]. A number of authors in the literature have defined system quality using different dimensions [29]. Later, DeLone and McLean [6] claimed that the system quality dimensions would show differences depending on the system characteristics. In this regard, the concept of perceived system quality could be defined by the system's flexibility, its skills to communicate with other information systems, response/feedback period, compatibility of use and clarity of the commands offered to users [4].

Defining the linkage between system quality and technology acceptance behaviour, DeLone and McLean [6] put forward a causal-explanatory model of how system quality influences usage and user satisfaction. Thereafter, a stream of work either developing or criticizing DeLone and McLean's model [6] emerged in the literature.

Green et al. [30] examined the impact of software development productivity and system quality on technology acceptance as well as use of the system. They found that system quality was related to perceived usefulness dimension of technology acceptance model propounded by Davis [1] as well as relative advantage dimension of diffusion of innovation theory put forward by Roger [3]. The implication of this study indicated system quality and system use were in relation. Another aspect of the system quality for innovation adoption was discussed by Ravichandran [31] who evaluated system quality as Total Quality Management perspective and proposed the quality of a system had a strategic priority especially initiating innovation. On the other hand, Rana et al.'s [23] meta-analytic research argued quality of a system on the basis of DeLone and McLean's [6] model for information system success. However, there was no significant association between system quality and intention to use for e-Government systems. Nevertheless, Ayo et al. [32] proposed to explain e-banking users' attitudes and behaviours with e-service quality as well as customer satisfaction, and they found e-service quality moderately relates to actual use as well as attitudes toward the system.

Previous researches have indicated the relationship between system quality and system use on technology acceptance model grounds, but there is a relative lack of research that represented this relation on the basis of diffusion of innovation theory in the literature. Ayo et al. [32] defined three dimensions of diffusion of innovation (relative advantage, complexity and compatibility) to explain attitude towards system. However, there was no direct path between system quality and diffusion of innovation dimensions, so we proposed the following hypothesis:

Hypothesis 1: Diffusability of innovation mediates the relationship between perceived system quality and information system success measured by system usage.

\subsection{Personal Innovativeness}

In addition to system feature search for the purpose of defining technology acceptance or innovation diffusion, the characteristics of the individuals employing the system should be examined. Even if the system has a perfect design, it cannot operate fully in the event that the individual's skills and personal innovativeness are not at a certain level.

Innovation researches indicated that personal innovativeness originated from the differences in cognitive styles of individuals [8]. Shifting in perspective from habits of mind to active thinking, Louis and Sutton [33] propounded some conditions to perform active thinking of individuals, so these conditions paved the way for 
innovative use behaviour [8]. Novelty, discrepancy and deliberate conditions are required for active thinking which was derived from conscious cognitive activity [33]. So, individuals presumably could perceive novel situation or discrepancy easily and incline to use new system or technology if they have higher level innovativeness [8].

Personal innovativeness refers to the "adaptation of certain individuals or departments to innovation sooner than other members of the social system" [3]. Agarwal and Prasad [34] define personal innovativeness as the eagerness to try any new information technology. From these definitions, personal innovativeness can be considered as an antecedent for technology acceptance behaviour. Lu [24] described personal innovativeness in information technology as a symbol of risk-taking inclination that some of individuals have but not others. Accordingly, highly innovative individuals could endure risk relating to system changes and most probably to use/adopt innovative system. The higher personal innovativeness is, the more positive beliefs individuals have towards new technologies [35]. Furthermore, Lewis et al. [35] contributed to technology acceptance model adding the two individual factors, personal innovativeness and self-efficacy. Mao et al. [36] asserted that an innovative approach towards technological innovation improves the perceived usefulness in view of relative advantage on the diffusion of innovation.

Explaining adoption of a new system/technology, several researchers examined the level of innovativeness of individuals $[8,16]$. They all found personal innovativeness played a major role in intention to use. However, some studies evaluated personal innovativeness as an antecedent [37], others as a moderating effect on behavioural intentions [38]. Thus, the personal innovativeness of the individuals could be evaluated as one of the determinants of technology acceptance behaviour. As mentioned before, DeLone and McLean's model [6] indicated a significant relationship between system quality and technology acceptance; on the other hand, Seddon [39] criticizes DeLone and McLean's model [6] for not including a feedback loop from individual impact to usage or user satisfaction. In light of this gap in the literature, we propose the following hypothesis:

Hypothesis 2: Diffusability of innovation mediates the relationship between personal innovativeness and information system success measured by system usage.

On the basis of the literature review and hypotheses, the research model of the study is presented in Fig. 1.

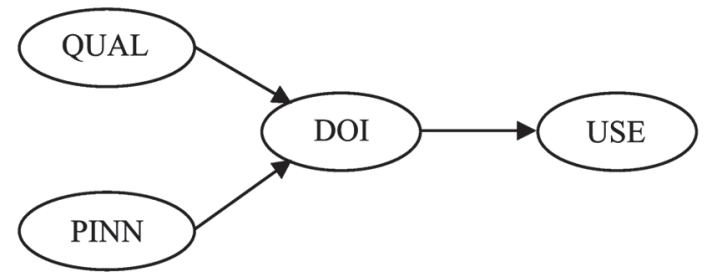

Figure 1 The proposed model, PINN = personal innovativeness, $\mathrm{QUAL}=$ perceived system quality, $\mathrm{DOI}=$ diffusability of innovation, USE = information system success measured by system usage

\section{METHOD}

\subsection{Participants}

The issue most identified in the literature is that the emerging stream of work on technology acceptance as well as innovation diffusion has been done in private sector
[40], while public sector research remains relatively sparse. To fill this gap, administrative personnel working at a state university in Turkey (126 male, 136 female), ranging in age from 22 to 64, formed the sample of present study. These administrative personnel work in state universities but are not academicians; rather, they work as government officers in the various branches of universities. After an electronic documentation management system was implemented by the government institutions, employees in the institutions had difficulty in accepting this technology.

\subsection{Measures \\ 3.2.1 Diffusability of Innovation}

As mentioned earlier, the diffusion of innovation construct was defined in five dimensions by Rogers [3]: relative advantage, compatibility, complexity, observability and trialability. Later, Moore and Benbasat [2] added the dimensions of image and result demonstrability to eliminate the low level of validity and reliability seen in previous research. In addition, Moore and Benbasat [2] developed an instrument in both long and short versions to measure individual adaptation to information technology innovation. Reliability and construct validity of the 38 -item long version instrument was measured, but only the 25 -item short version was recommended for future research. Their explanatory factor analysis results indicated that all constructs loaded in their relevant factor, but only relative advantage and compatibility gather in a factor. Furthermore, all factors' reliability scores are shown in Tab. 1. After that, Agarwal and Prasad [20] defined these seven dimensions presented by Moore and Benbasat's [2] previous research, as innovation characteristics. Later, Carter and Belanger [21] evaluated the previous innovation adaptation research and eliminated the dimensions that did not give good reliability and validity scores (visibility, trialability and result demonstrability). Looking at explanatory factor analysis of Carter and Belanger's research [21] in detail, it can be seen relative advantage and compatibility gathered in a factor.

Table 1 Reliability scores of previous and present researches for diffusion of

\begin{tabular}{|l|c|c|c|c|c|}
\hline \multicolumn{1}{|c|}{ Innovation scale } & Item & {$[2]$} & {$[20]$} & {$[21]$} & Present \\
\hline Relative Advantage & 5 & 0,90 & 0,90 & 0,84 & 0,94 \\
\hline Ease of Use & 4 & 0,84 & 0,80 & 0,86 & 0,89 \\
\hline Compatibility & 3 & 0,86 & 0,84 & 0,83 & 0,90 \\
\hline Image & 3 & 0,79 & 0,85 & 0,81 & 0,91 \\
\hline Result Demonstra. & 4 & 0,79 & 0,81 & - & 0,79 \\
\hline Visibility & 2 & 0,83 & 0,51 & - & 0,62 \\
\hline Trialability & 2 & 0,71 & 0,30 & - & 0,51 \\
\hline
\end{tabular}

Diffusion of innovation researches as mentioned before have investigated innovation diffusion in fact, but this study aimed to examine the ability to diffuse an innovation, entitled "diffusability of innovation". So we used the short version of Moore and Benbasat's adaptation of information technology innovation scale [2], whose reliability and construct validity were confirmed by Agarwal and Prasad [20] as well as Carter and Belanger [21]. The scale contains 25 items anchored by $1=$ strongly disagree and $5=$ strongly agree. First, we conducted an explanatory factor analysis, which resulted in 6 factors. Relative advantage and compatibility dimensions were 
gathered in a single factor as in previous research $[2,21]$. One of the visibility items was dropped and then the scale's items were gathered in relevant factors of original scale of Moore and Benbasat's research [2]. Thus, diffusability of innovation was explained with the factors of image, ease of use (as the reverse version of complexity), result demonstrability, visibility, trialability, relative advantage and compatibility. All of the factors' Cronbach Alpha values are presented in Tab. 1. Visibility and trialability scores are relatively low, but these scores roughly correspond to previous researches'.

Unlike previous studies, as shown in Tab. 1, we conducted confirmatory factor analysis on the diffusability of innovation scale with LISREL 8.5 package program. The confirmatory factor analysis goodness of fit index scores indicated a good fit to the data: $X^{2} / d f(2,21: N=262)$; $p<0,05 ; R M E S A=0,068 ; G F I=0,86 ; R M R=0,063 ; C F I$
$=0,94 ; I F I=0,94 ; G F I=0,87(90 \%$ confidence interval for $R M S E A=0,060-0,076)$. All of the factor loadings are statistically significant, and standardized values ranged from 0,64 to 0,22 (see in Appendix). Explanatory factor analyses results of previous and the present research indicated that the relative advantage and compatibility factors should be a single factor. Confirmatory factor analysis was done again after the two factors were combined. However, confirmatory factor analysis did not produce better goodness of fit statistics: $X^{2} / d f(3,07: N=$ 262); $p<0,05 ; R M E S A=0,089 ; R M R=0,070 ; C F I=0,90$; $I F I=0,90 ; G F I=0,82(90 \%$ Confidence Interval for RMSEA $=0,081-0,097)$. Comparing the two structures of measurement instrument, it can be seen that the first one (not combining the factors of relative advantage and compatibility) is better. Thus, we used the first version of instrument to test the measurement and structural model in the following section.

Table 2 Means, standard deviations and correlations among observed variables used in model

\begin{tabular}{|c|c|c|c|c|c|c|c|c|c|c|c|c|c|c|c|c|c|c|}
\hline Variable & $\mathrm{M}$ & $\mathrm{SD}$ & RA & EU & $\mathrm{CO}$ & IM & $\mathrm{RD}$ & VI & TR & QUA1 & QUA2 & PI1 & PI2 & PI3 & AU1 & AU2 & AU3 & AU4 \\
\hline RA & 3,52 & 1,06 & 1 & & & & & & & & & & & & & & & \\
\hline EU & 3,59 & 0,88 & $0,70^{* *}$ & 1 & & & & & & & & & & & & & & \\
\hline $\mathrm{CO}$ & 3,30 & 1,02 & $0,81^{* *}$ & $0,67^{* *}$ & 1 & & & & & & & & & & & & & \\
\hline IM & 2,31 & 1,06 & $0,42^{* *}$ & $0,34^{* *}$ & $0,43^{* *}$ & 1 & & & & & & & & & & & & \\
\hline RD & 3,43 & 0,84 & $0,64^{* *}$ & $0,75^{* *}$ & $0,68^{* *}$ & $0,49^{* *}$ & 1 & & & & & & & & & & & \\
\hline VI & 3,46 & 0,93 & $0,26^{* *}$ & $0,25^{* *}$ & $0,33^{* *}$ & 0,11 & $0,29^{* *}$ & 1 & & & & & & & & & & \\
\hline TR & 3,69 & 0,82 & $0,27^{* *}$ & $0,18^{* *}$ & $0,29^{* *}$ & $0,20^{* *}$ & $0,21^{* *}$ & $0,19^{* *}$ & 1 & & & & & & & & & \\
\hline QUA1 & 3,24 & 0,84 & $0,68^{* *}$ & $0,63^{*}$ & $0,64^{* *}$ & $0,40^{* *}$ & $0,66^{* *}$ & $0,21^{* *}$ & $0,15^{* *}$ & 1 & & & & & & & & \\
\hline QUA2 & 3,21 & 0,76 & $0,63^{* *}$ & $0,64^{* *}$ & $0,62^{* *}$ & $0,40^{* *}$ & $0,67^{* *}$ & $0,22^{* *}$ & $0,15^{*}$ & $0,83^{* *}$ & 1 & & & & & & & \\
\hline PI1 & 3,47 & 1,16 & $0,19^{* *}$ & $0,21^{* *}$ & $0,25^{* *}$ & $0,17^{* *}$ & $0,24^{* *}$ & $0,15^{*}$ & $0,27^{* *}$ & $0,15^{*}$ & $0,17^{* *}$ & 1 & & & & & & \\
\hline PI2 & 2,92 & 1,18 & 0,08 & 0,04 & 0,11 & 0,06 & 0,09 & 0,03 & 0,10 & 0,08 & $0,13^{*}$ & $0,49^{* *}$ & 1 & & & & & \\
\hline PI3 & 3,75 & 1,04 & $0,23^{* *}$ & $0,25^{* *}$ & $0,25^{* *}$ & $0,19^{* *}$ & $0,26^{* *}$ & 0,10 & $0,33^{* *}$ & $0,20^{* *}$ & $0,22^{* *}$ & $0,54^{* *}$ & $0,36^{* *}$ & 1 & & & & \\
\hline AU1 & 3,61 & 1,18 & $0,41^{* *}$ & $0,38^{* *}$ & $0,52^{* *}$ & $0,22^{* *}$ & $0,40^{* *}$ & $0,32^{* *}$ & $0,31^{* *}$ & $0,27^{* *}$ & $0,28^{* *}$ & $0,30^{* *}$ & $0,24^{* *}$ & $0,24^{* *}$ & 1 & & & \\
\hline AU2 & 3,62 & 1,16 & $0,49^{* *}$ & $0,43^{* *}$ & $0,56^{* *}$ & $0,26^{* *}$ & $0,47^{* *}$ & $0,30^{* *}$ & $0,23^{* *}$ & $0,39^{* *}$ & $0,39^{* *}$ & $0,32^{* *}$ & $0,15^{*}$ & $0,21^{* *}$ & $0,80^{* *}$ & 1 & & \\
\hline AU3 & 3,56 & 1,23 & $0,47^{* *}$ & $0,38^{*}$ & $0,53^{* *}$ & $0,22^{* *}$ & $0,42^{* *}$ & $0,32^{* *}$ & $0,23^{* *}$ & $0,37^{* *}$ & $0,33^{* *}$ & $0,29^{* *}$ & $0,21^{* *}$ & $0,21^{* *}$ & $0,86^{* *}$ & $0,85^{* *}$ & 1 & \\
\hline AU4 & 3,64 & 1,19 & $0,54^{* *}$ & $0,48^{* *}$ & $0,58^{* *}$ & $0,33^{* *}$ & $0,49^{* *}$ & $0,33^{* *}$ & $0,21^{* *}$ & $0,47^{* *}$ & $0,45^{* *}$ & $0,34^{* *}$ & $0,18^{* *}$ & $0,24^{* *}$ & $0,67^{* *}$ & $0,83^{* *}$ & $0,76^{* *}$ & 1 \\
\hline
\end{tabular}

$N=262$; The first six constructs are factors of Diffusion of Innovation (DOI) construct where RA= Relative Advantage; EU= Ease of Use; CO= Compatibility; IM = Image, $\mathrm{RD}=$ Result Demonstrability, $\mathrm{VI}=$ Visibility; $\mathrm{TR}=$ Trialability. QUA1-QUA2 = two parcels of perceived system quality (higher scores show higher level of perception about system quality); PI1-PI3 items of PINN for the construct of personal innovativeness; AU1-AU4 items of the USE for information system success measured by system usage (higher scores indicates higher levels of current usage). ${ }^{*} p<0,05 ; * * p>0,01$

\subsubsection{Personal Innovativeness}

The personal innovativeness construct is measured by personal innovativeness in the domain of information technology scale developed by Agarwal and Prasad [34]. The scale consists of four items and they settled in a factor with acceptable internal consistency and Cronbach's alpha value $(0,84)$. Yi et al. [38] used Agarwal and Prasad's personal innovativeness scale [34] in their research but they had to eliminate a reversed-scored item and measure the construct with three items in order to obtain better internal consistency $(\alpha=0,85)$. On the basis of Agarwal and Prasad's [34] scale, we measured personal innovativeness with 4 items ranging from strongly disagree (1) to strongly agree (5). Similarly to Yi et al.'s study [38], we had to drop a reverse-coded item in order to avoid a problem in factor loadings. Finally, in this study, Cronbach's alpha coefficient was found: 0,73 .

\subsubsection{Perceived System Quality}

The construct of perceived system quality is investigated in terms of system properties in the literature, especially flexibility, integration, response time, error recovery, convenience of access and system language [4].
Many system properties were defined by Bailey and Pearson [29], who developed a measurement instrument for them and explained many factors that predict computer user satisfaction. Later, Livari [4] adopted some of Bailey and Pearson's [29] dimensions to measure perceived system quality and found 0,97 internal consistency. Finally, we adopted Livari's system quality scale [4] and measured the construct with 6 items anchored at $1=$ strongly disagree and $5=$ strongly agree. In the present study, the Cronbach's Alpha coefficient was found 0,86.

\subsubsection{Information System Success Measured by System Usage}

System use is a component of the technology acceptance model $[1,20]$ and indicates information system success or failure according to some authors $[6,14]$. On the basis of these authors' research, we used the self-predicted system use scale developed by Davis et al. [1]. Agarwal and Prasad [20] adopted this self-report scale for their study and found acceptable reliability $(\alpha=0,92)$. We evaluated respondents using 4 items to measure their system usage on a five-point Likert-type items anchored by $1=$ "strongly disagree" and $5=$ "strongly agree". The 
Cronbach's alpha internal consistency coefficient for the present data showed acceptable reliability $(\alpha=0,94)$.

\subsection{Results \\ 3.3.1 Descriptive Statistics}

Tab. 2 indicates means, standard deviations and zeroorder correlations for the 16 observed variables. Kurtosis and skewness values were less than 1, with skewness values ranging from 0,15 to 0,91 and kurtosis values from 0,01 to 0,91 ; indicating no normality assumption issues.

\subsubsection{Test of the Measurement Model}

The measurement model explained all possible relations of the observed variables to their underlying constructs were enabled to intercorrelate freely [41]. In structural equation modeling, measurement model testing should be done before structural model testing [42]. The present research has four latent variables in the structural equation modeling: PINN (personal innovativeness), QUAL (system quality), DOI (diffusability of innovation, and USE (self-reported usage). The items of "personal innovativeness" and "information system success measured by system usage" scales were used as indicators of PINN and USE latent constructs, respectively, because the measure of PINN had three items and that of USE had four items. The QUAL latent variable was defined using the two parcels; on the other hand, the DOI construct was defined by seven original factors; relative advantage, ease of use, compatibility, image, result demonstrability, visibility, and trialability.

The preliminary test of the measurement model results showed an acceptable fit to the data, $X^{2} / d f(3,07: N=262)$; $p<0,05 ;$ RMESA $=0,089 ; R M R=0,067 ; C F I=0,92 ; I F I$ $=0,92 ; G F I=0,87(90 \%$ Confidence Interval for $R M S E A$ $=0,078-0,01)$. However, modification that is represented on Lisrel output recommended adding error covariance between AU1 to AU3 and AU2 to AU4. After adding covariance between those items, goodness of fit statistics produces better fit values, $X^{2} / d f(2,46: N=262) ; p<0,05$; $R M E S A=0,075 ; R M R=0,065 ; C F I=0,94 ; I F I=0,94$; $G F I=0,90(90 \%$ Confidence Interval for $R M S E A=0,063-$ $0,087)$. Thus, the second model is suitable as a structural model to produce better fit values of the data. The parameter estimates of the measurement model are depicted in Fig. 2. The $t$ values of the factor loading ranged from 4,53 to 19,32, indicating that all of them loaded significantly in their relevant constructs. The correlation coefficients among the constructs are higher than zeroorder correlation in Tab. 2, so it is possible to say that errors are eliminated by constructing the latent variable.

All of the correlations among latent variables were found to be statistically significant, as predicted. First, personal innovativeness was correlated with diffusability of innovation and diffusability of innovation was correlated with system usage, and there was significant relationship between personal innovativeness and system usage. These results are important for the Baron and Kenny [43] methodology. Second, perceived system quality was associated with diffusability of innovation, and diffusability of innovation was associated with system usage; in addition, the relationship between perceived system quality and usage was significant. Finally, these significant relations indicated that Baron and Kenny's methodology [43] should be used to test mediations of the structural model.

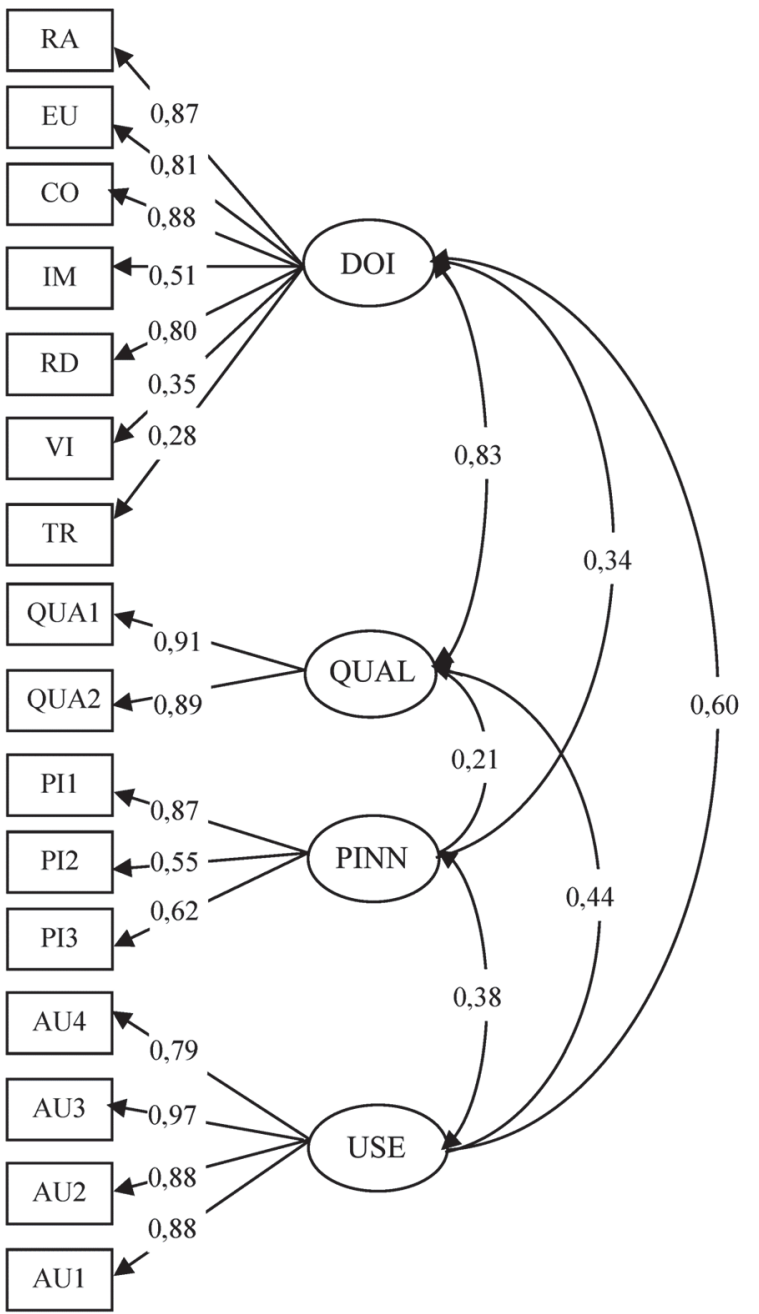

Figure 2 Standardized solution estimates of the measurement model. $N=262$; DOI diffusability of innovation; QUAL perceived system quality; PINN personal innovativeness; USE information system success measured by system usage; First seven observed variables are the factors of diffusability of Innovation (DOI); $\mathrm{RA}$ relative advantage; $\mathrm{EU}=$ ease of use; $\mathrm{CO}=$ compatibility; $\mathrm{IM}=$ image, $\mathrm{RD}=$ result demonstrability, $\mathrm{VI}=$ visibility; $\mathrm{TR}=$ trialability. $\mathrm{QUA1}-\mathrm{QUA} 2=$ two parcels of perceived system quality; PI1-PI3 items of personal innovativeness; AU1-AU4 items of information system success measured by usage. All parameters are significant at the $p=0,01$.

\subsubsection{Test of the Structural Model}

After proposing the model indicated in Fig. 1, we analyzed it using the LISREL 8.5 package program and obtained an acceptable fit of data: $X^{2} / d f(2,46: N=262) ; p$ $<0,05 ; R M E S A=0,075 ; R M R=0,065 ; C F I=0,94 ; I F I=$ 0,94; $G F I=0,90(90 \%$ Confidence Interval for $R M S E A=$ $0,063-0,087)$. In order to obtain the best fit to the data, we used the nested model strategy developed by Anderson and Gerbing [42] for the mediation analyses. Returning to the model indicated in Figure 2 and its analysis results, we saw that the $t$ value for the path from perceived system quality (QUAL) to system usage (USE) $(t=-1,41)$ was not significant. After we deleted the path from the model, the model produced the following goodness of fit statistics: $X^{2} / d f(2,48: N=262) ; p<0,05 ; R M E S A=0,075 ; R M R=$ 0,$066 ; \quad C F I=0,94 ; \quad I F I=0,94 ; G F I=0,90(90 \%$ 
Confidence Interval for $R M S E A=0,063-0,087)$. The ChiSquare difference test $(240,06-237,01=3,75 d f=1 ; p>$ $0,05)$ indicated that deleting the path did not affect the model fit significantly. Furthermore, we did not add this path to the model in order to follow the parsimony principle.

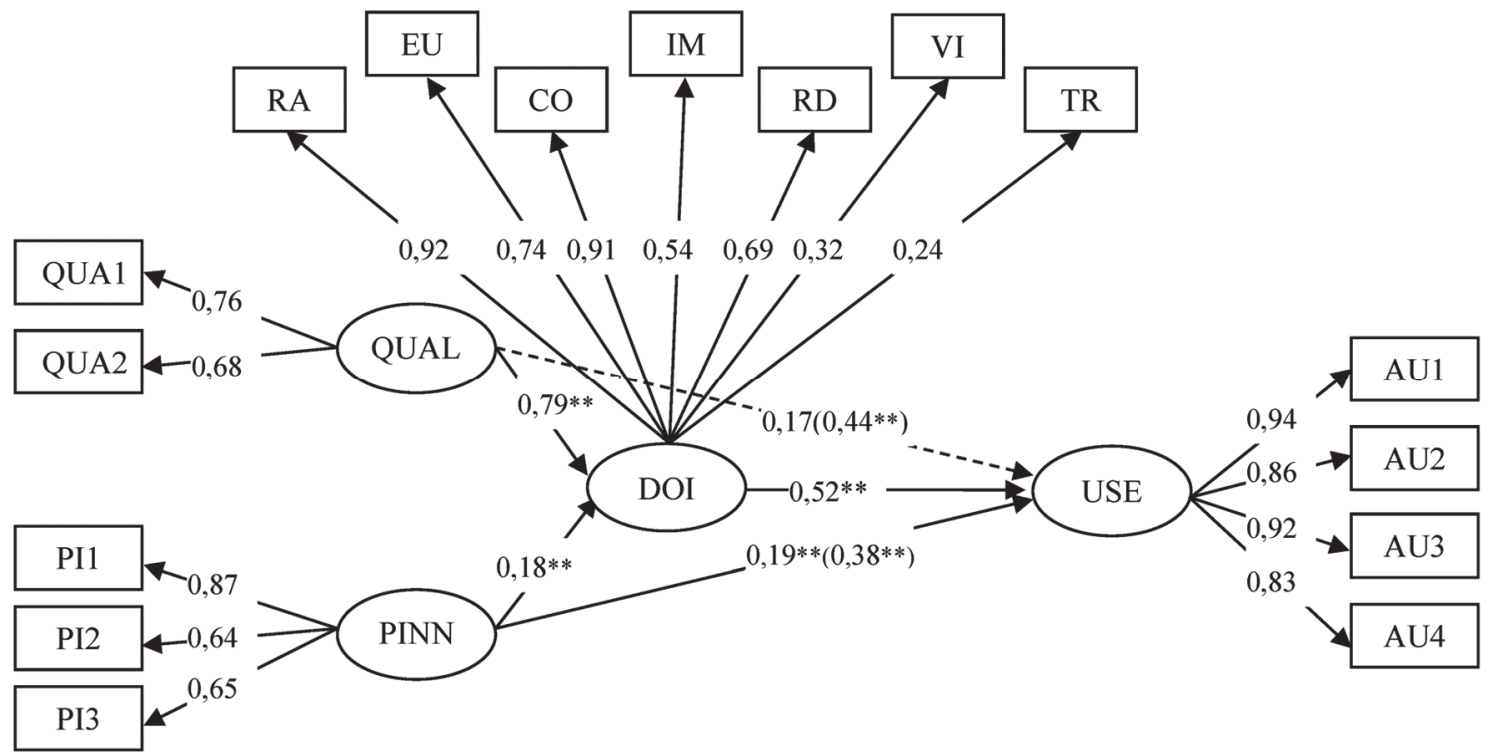

Figure 3 Standardized parameter estimates of the final structural model. $N=262$, The dashed line indicates non-significant paths; numbers in parentheses refer to coefficients for the direct paths before the mediator is included in the model; QUAL perceived system quality; PINN personal innovativeness; DOI diffusability of innovation; USE information system success measured by system usage; QUA1 and QUA2 parcels of perceived system quality; PI1-PI3 items of the personal innovativeness scale; RA relative advantage, EU ease of use, CO compatibility, IM Image, RD result demonstrability, VI visibility, TR trialability are factors of DOI; AU1-AU4 items of information system success measured by usage scale. All factor loadings are significant at $p=0,01 .{ }^{* *} p<0,01$

For alternative model testing, another mediation analysis could be conducted on the path from personal innovativeness (PINN) to system usage (USE) according to Baron and Kenny's [43] methodology. Deleting this path to the model produced the following goodness of fit statistics: $X^{2} / d f(2,52: N=262) ; p<0,05 ; R M E S A=0,076$; $R M R=0,074 ; C F I=0,94 ; I F I=0,94 ; G F I=0,90(90 \%$ Confidence Interval for $R M S E A=0,064-0,088)$. According to the nested model strategy [42], deleting this path produced worse goodness of fit scores than the previous ones (Chi-Square difference 244,51-237,01 = 7,50 df=1; $p<0,05)$. Thus, this path should not be omitted from the model. On the basis of mediation analyses, we found that the path from perceived system quality to system usage was non-significant. Thus, we could say that diffusability of innovation fully mediated the relationship between perceived system quality and system usage, according to Baron and Kenny [43]. Therefore, the first hypothesis was accepted. On the other hand, the $\mathrm{t}$ standardized solution value of the path from personal innovativeness to system usage was 0,38 in the measurement model and 0,19 in the structural model. Hence, we could say that diffusability of innovation partially mediated the relationship between personal innovativeness and system usage. Thus, hypothesis 2 was partially accepted. The final model with standardized estimates is shown in Fig. 3.

\section{CONCLUSION}

Innovation is a key construct due to its valuable contribution to all parts of the world. After introducing an innovation, its diffusability is another important issue waiting to be solved by companies. Therefore, diffusability of innovation should be evaluated in both technical and behavioural aspects, in addition to investigation of knowledge management and the organizational behaviour framework. With this in mind, we defined perceived system quality as the technical aspect and personal innovativeness as the behavioural aspect of the technology acceptance concept to explain diffusability of innovation.

Whether or not an information technology innovation spreads in an organization is investigated at the root of its usage by employees/users. This also shows the information system success of a new system. Parallel with the DeLone ad McLean's model [6, 7], system quality was identified as one of the predictors of success of the system in this research. Furthermore, present researchers defined personal innovativeness as another determinant of information system success in the research model. So this theoretical model was proved empirically on the adaptation of electronic document management systems framework. Based on the literature review of technology acceptance and diffusion of innovation, especially public personnel's low and limited usage of information and communication technologies $[12,13]$, we investigated electronic document management systems as an innovation for governmental institutions in terms of their diffusability through the university administrative personnel. A measurement instrument was applied to this sample and attained adequately good fit to explain the data. An alternative model was also tested, as indicated by explanatory and confirmatory factor analyses.

A measurement model was designed to explain the relationships among the concepts of personal innovativeness, perceived system quality, diffusability of innovation and system usage. As all possible relations of observed variables produced good fit statistics, we proposed a structural model.

The results illustrate that system quality is associated with system usage (as in $[6,30]$ ) and diffusability of 
innovation. However, perceived system quality is not related to system usage when controlling for diffusability of innovation. Consequently, diffusability of innovation fully mediates the relationship between perceived system quality and information system success measured by system usage. Thus, it can be said there is an indirect relationship between perceived system quality and information system success by means of diffusability of innovation. So public personnel is inclined to use a system once they have perceived quality about the system and environment is convenient for diffusion of this kind of innovation or adaptation. Results indicate that no matter how much quality a system has, employees are not apt to use the system as long as organizational context is suitable for innovation diffusion. Users in the organization are prone to use a new system or a system can be implemented successfully, providing that this system gives some advantages to users when they do their work, it enables user to observe and try itself, it is not complex to learn, it is compatible to their shape of work and beneficial to demonstrate results and it presents a positive image for users.

Findings indicate that there is a significant relationship between personal innovativeness and system usage as in previous studies [35, 36]. In addition, personal innovativeness is associated with diffusability of innovation. Furthermore, there is a relationship between personal innovativeness and system usage directly and, by means of diffusability of innovation, indirectly. In other words, to explain the effect of personal innovativeness on information system success measured by system usage, we should investigate diffusability of innovation. As shown in this investigation, diffusability of innovation partially mediates the relationship between personal innovativeness and information system success measured by usage. As regards an information system success on the organizational setting, users' skills and personal innovativeness should be at a certain level and then climate of the organization is appropriate for diffusion of innovation or adaptation.

This paper builds on and extends earlier works on the relationships among perceived system quality, personal innovativeness, diffusability of innovation and information system success measured by system usage. Turan et al. [44] have considered all those variables together and identified relations among them, which will help to shape their hypotheses for this following study. Some of their propositions have been formulated into hypotheses and then tested in the present research in the public sector.

Our research attempts to make several contributions to the literature, particularly proposing the model and identifying both technical and behavioural antecedents of diffusability of innovation. After Thakur and Srivastava's [16] research which examined unified theory of acceptance and use of technology as a latent construct, evaluating diffusion of innovation as a single latent construct and entitled it diffusability of innovation, was another contribution of this research to the literature. In addition, information system success is predicted by personal innovativeness and perceived system quality directly and, by means of diffusability of innovation, indirectly. We evaluated only one behavioural and one technical antecedent of diffusability of innovation and of information system success measured by system usage. Nevertheless, previous researches indicated other technical (e.g. information quality, service quality) and behavioural antecedents (e.g. organizational innovativeness, user resistance or anxiety) of those variables. So other antecedents can be evaluated in further studies.

\section{REFERENCES}

[1] Davis, F. D. (1989). Perceived usefulness, perceived ease of use, and user acceptance of information technology. MIS Quarterly, 13(3), 319-340. https://doi.org/10.2307/249008

[2] Moore, G. C. \& Benbasat, I. (1991). Development of an instrument to measure the perceptions of adopting an information technology innovation. Information Systems Research, 2(3), 192-222. https://doi.org/10.1287/isre.2.3.192

[3] Rogers, E. M. (1983). Diffusion of innovations. New York: The Free Press.

[4] Livari, J. (2005). An empirical test of the DeLone-McLean model of information system success. ACM SIGMIS Database, 36(2), 8-27. https://doi.org/10.1145/1066149.1066152

[5] Urbach, N. \& Müller, B. (2011). The updated DeLone and McLean model of information systems success. Information Systems Theory Integrated Series in Information Systems, 118. https://doi.org/10.1007/978-1-4419-6108-2_1

[6] DeLone, W. H. \& McLean, E. R. (1992). Information systems success: The quest for the dependent variable. Information Systems Research, 3(1), 60-95. https://doi.org/10.1287/isre.3.1.60

[7] DeLone, W. H. \& McLean, E. R. (2003). The DeLone and McLean model of information systems success: A ten-year update. Journal of Management Information Systems, 19(4), 9-30. https://doi.org/10.1080/07421222.2003.11045748

[8] Lu, J. (2014). Are personal innovativeness and social influence critical to continue with mobile commerce? Internet Research, 24(2), 134-159. https://doi.org/10.1108/IntR-05-2012-0100

[9] Crewson, P. E. (1997). Public-service motivation: Building empirical evidence of incidence and effect. Journal of Public Administration Research and Theory, 7(4), 499-518. https://doi.org/10.1093/oxfordjournals.jpart.a024363

[10] Fernandez, S. \& Pitts, D. W. (2011). Understanding employee motivation to innovate: Evidence from front line employees in United States Federal Agencies. Australian Journal of Public Administration, 70(2), 202-222. https://doi.org/10.1111/j.1467-8500.2011.00726.x

[11] Wise, L. R. (1999). The use of innovative practices in the public and private sectors: The role of organizational and individual factors. Public Productivity \& Management Review, 23(2), 150-168. https://doi.org/10.2307/3380776

[12] Mbatha, B. T., Ocholla, D. N., \& Roux, J. L. (2011). Diffusion and adoption of ICTs in selected government departments in KwaZulu-Natal, South Africa. Information Development, 27(4), 251-263. https://doi.org/10.1177/0266666911424864

[13] Ntetha, M. A. (2010). The access, interaction, use and impact of information and communication technologies among civil servants in the Umhlathuze area: A social informatics study. Master's thesis.

[14] Danet T. L. (2006). A study of the impact of users' involvement, resistance and computer self-efficacy on the success of a centralized identification system implementation. Doctoral dissertation.

[15] Ma, Q. \& Liu, L. (2004). The technology acceptance model: A meta-analysis of empirical findings. Journal of Organizational and End User Computing, 16(1), 59-72. https://doi.org/10.4018/joeuc.2004010104 
[16] Thakur, R. \& Srivastava, M. (2014). Adoption readiness, personal innovativeness, perceived risk and usage intention across customer groups for mobile payment services in India. Internet Research, 24(3), 369-392. https://doi.org/10.1108/IntR-12-2012-0244

[17] Wiegand, C., Abel, M., Ruth, P., Elsner, P., \& Hipler, U. (2015). In vitro assessment of the antimicrobial activity of wound dressings: Influence of the test method selected and impact of the $\mathrm{pH}$. Journal of Materials Science: Materials in Medicine, 26(1), 1-13. https://doi.org/10.1007/s10856-014-5343-9

[18] Le Roux, R. (2014). A matter of accuracy. nanobiochips in diagnostics and in research: Ethical issues as value tradeoffs. Science and Engineering Ethics, 21(2), 343-358. https://doi.org/10.1007/s11948-014-9550-z

[19] Frank, D. \& Milković, M. (2018). Evaluation of electronic programme guide adoption using UTAUT2 based model. Tehnicki Vjesnik - Technical Gazette, 25(3), 884-890. https://doi.org/10.17559/TV-20180601095518

[20] Agarwal, R. \& Prasad, J. (1997). The role of innovation characteristics and perceived voluntariness in the acceptance of information technologies. Decision Sciences, 28(3), 557582. https://doi.org/10.1111/j.1540-5915.1997.tb01322.x

[21] Carter, L. \& Bélanger, F. (2005). The utilization of egovernment services: Citizen trust, innovation and acceptance factors. Information Systems Journal, 15(1), 525. https://doi.org/10.1111/j.1365-2575.2005.00183.x

[22] Soto-Acosta, P., Ramayah, T., \& Popa, S. (2013). Explaining intention to use an enterprise resource planning system: a replication and extension. Tehnički Vjesnik - Technical Gazette, 20(3), 397-405.

[23] Rana N. P., Williams M. D., Dwivedi Y. K., \& Williams J. (2012). Theories and theoretical models for examining the adoption of e-government services. E-Service Journal, 8(2), 26-56. https://doi.org/10.2979/eservicej.8.2.26

[24] Chang, H. H., Huang, C. Y., Fu, C. S., \& Hsu, M. T. (2017) The effects of innovative, consumer and social characteristics on willingness to try nano-foods: Product uncertainty as a moderator. Information Technology \& People, 30(3), 653-690. https://doi.org/10.1108/ITP-10-2015-0266

[25] Therrien, S., Brauer, M., Fuller, D., Gauvin, L., Teschke, K., \& Winters, M. (2014). Identifying the leaders. Transportation Research Record: Journal of the Transportation Research Board, 2468(1), 74-83. https://doi.org/10.3141/2468-09

[26] Carter, P., Agarwal, R., \& Sambamurthy, V. (1999, December). Organizational innovation with information technologies: The cycle of adoption, adaptation, and use. Paper presented at the AMCIS, 584-587.

[27] Chang, Y., Hsu, P., \& Shiau, W. (2014). An empirical study of managers' usage intention in BI. Cognition, Technology \& Work, 16(2), 247-258. https://doi.org/10.1007/s10111-013-0261-z

[28] Gable, G., Sedera, D., \& Chan, T. (2008). Reconceptualizing information system success: The IS-impact measurement model. Journal of the Association for Information Systems, 9(7), 377-408. https://doi.org/10.17705/1jais.00164

[29] Bailey, J. E. \& Pearson, S. W. (1983). Development of a tool for measuring and analyzing computer user satisfaction. Management Science, 29(5), 530-545. https://doi.org/10.1287/mnsc.29.5.530

[30] Green, G. C., Hevner, A. R., \& Collins, R. W. (2005). The impacts of quality and productivity perceptions on the use of software process improvement innovations. Information and Software Technology, 47(8), 543-553. https://doi.org/10.1016/j.infsof.2004.10.004
[31] Ravichandran, T. (2000). Swiftness and intensity of administrative innovation adoption: An empirical study of TQM in information systems. Decision Sciences, 31(3), 691724. https://doi.org/10.1111/j.1540-5915.2000.tb00939.x

[32] Ayo, C. K., Oni, A. A., Adewoye, O. J., \& Eweoya, I. O. (2016). E-banking users' behaviour: E-service quality, attitude, and customer satisfaction. International Journal of Bank Marketing, 34(3), 347-367. https://doi.org/10.1108//JBM-12-2014-0175

[33] Louis, M. R. \& Sutton, R. I. (1991). Switching cognitive gears: From habits of mind to active thinking. Human Relations, 44(1), 55-76. https://doi.org/10.1177/001872679104400104

[34] Agarwal, R. \& Prasad, J. (1998). A conceptual and operational definition of personal innovativeness in the domain of information technology. Information Systems Research, 9(2), 204-215. https://doi.org/10.1287/isre.9.2.204

[35] Lewis, W., Agarwal, R., \& Sambamurthy, V. (2003). Sources of influence on beliefs about information technology use: An empirical study of knowledge workers. MIS Quarterly, 27(4), 657-678. https://doi.org/10.2307/30036552

[36] Mao, E., Srite, M., Thatcher, J. B., \& Yaprak, O. (2005). A research model for mobile phone service behaviors: Empirical validation in the U.S. and Turkey. Journal of Global Information Technology Management, 8(4), 7-28. https://doi.org/10.1080/1097198X.2005.10856406

[37] Kwon, O., Choi, K., \& Kim, M. (2007). User acceptance of context-aware services: Self-efficacy, user innovativeness and perceived sensitivity on contextual pressure. Behaviour \& Information Technology, 26(6), 483-498. https://doi.org/10.1080/01449290600709111

[38] Yi, M. Y., Fiedler, K. D., \& Park, J. S. (2006). Understanding the role of individual innovativeness in the acceptance of itbased innovations: Comparative analyses of models and measures. Decision Sciences, 37(3), 393-426. https://doi.org/10.1111/j.1540-5414.2006.00132.x

[39] Seddon, P. B. (1997). A respecification and extension of the DeLone and McLean model of IS success. Information Systems Research, 8(3), 240-253. https://doi.org/10.1287/isre.8.3.240

[40] Venkatesh V., Morris M. G., Davis G. B., \& Davis F. D. (2003). User acceptance of information technology: Toward a unified view. MIS Quarterly, 27(3), 425-478. https://doi.org/10.2307/30036540

[41] Şimşek, Ö. F. \& Kuzucu, Y. (2012). The gap that makes us desperate: Paths from language to mental health. International Journal of Psychology, 47(6), 467-477. https://doi.org/10.1080/00207594.2011.645479

[42] Anderson, J. C. \& Gerbing, D. W. (1988). Structural equation modeling in practice: A review and recommended two-step approach. Psychological Bulletin, 103(3), 411-423. https://doi.org/10.1037/0033-2909.103.3.411

[43] Baron, R. M. \& Kenny, D. A. (1986). The moderator mediator variable distinction in social psychological research: Conceptual, strategic, and statistical considerations. Journal of Personality and Social Psychology, 51(6), 1173-1182. https://doi.org/10.1037/0022-3514.51.6.1173

[44] Turan, A., Tunç, A. Ö., \& Zehir, C. (2015). A theoretical model proposal: Personal innovativeness and user involvement as antecedents of unified theory of acceptance and use of technology. Procedia-Social and Behavioral Sciences, 210. https://doi.org/10.1016/j.sbspro.2015.11.327 


\section{Contact information:}

Aygul DONMEZ-TURAN, PhD, Assistant Professor

(Corresponding author)

Yildiz Technical University, Yildiz Technical University Davutpasa Campus,

Economics and Business Administration Faculty,

Organizational Behaviour Department,

34220, Istanbul/Turkey

E-mail: ayturan@yildiz.edu.tr

Cemal ZEHIR, PhD, Professor

Yildiz Technical University, Yildiz Technical University Davutpasa Campus,

Economics and Business Administration Faculty,

Management and Organization Department,

34220, Istanbul/Turkey

E-mail: czehir@yildiz.edu.tr

\section{APPENDIX: Result of the Confirmatory Factor Analysis of Diffusability of Innovation Scale}

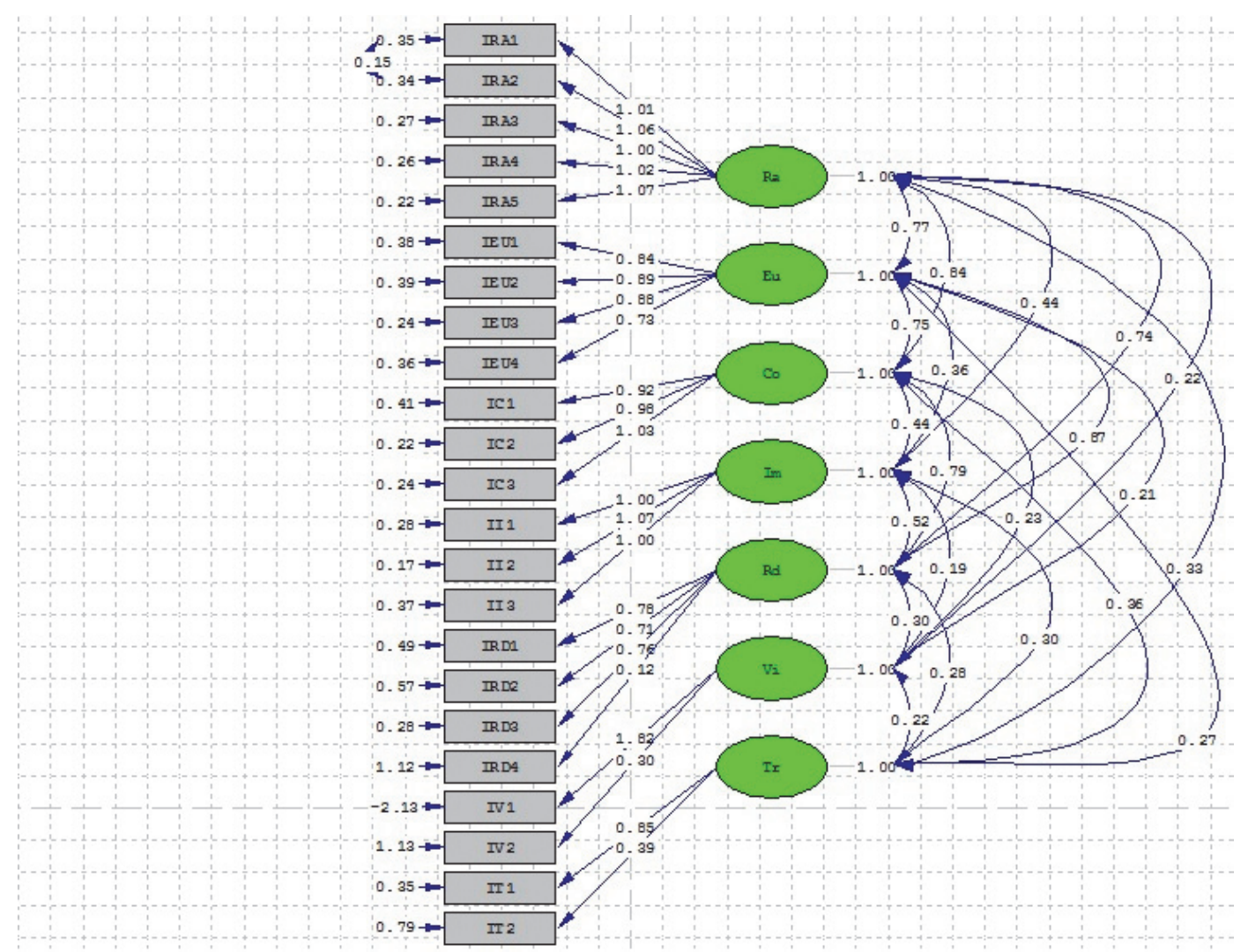

